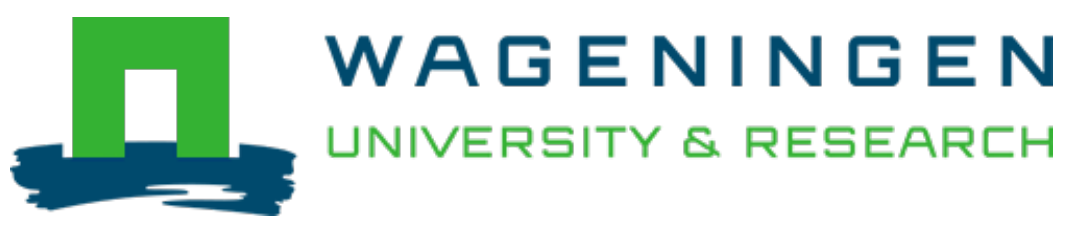

\title{
Mucoraceous moulds involved in the commercial fermentation of Sufu Pehtze
}

Antonie van Leeuwenhoek: Nederlandsch tijdschrift voor hygiëne, microbiologie en serologie

Han, B.; Kuijpers, F.A.; Thanh, N.V.; Nout, M.J.R.

https://doi.org/10.1023/B:ANTO.0000020157.72415.b9

This publication is made publicly available in the institutional repository of Wageningen University and Research, under the terms of article $25 \mathrm{fa}$ of the Dutch Copyright Act, also known as the Amendment Taverne. This has been done with explicit consent by the author.

Article $25 \mathrm{fa}$ states that the author of a short scientific work funded either wholly or partially by Dutch public funds is entitled to make that work publicly available for no consideration following a reasonable period of time after the work was first published, provided that clear reference is made to the source of the first publication of the work.

This publication is distributed under The Association of Universities in the Netherlands (VSNU) 'Article $25 \mathrm{fa}$ implementation' project. In this project research outputs of researchers employed by Dutch Universities that comply with the legal requirements of Article $25 \mathrm{fa}$ of the Dutch Copyright Act are distributed online and free of cost or other barriers in institutional repositories. Research outputs are distributed six months after their first online publication in the original published version and with proper attribution to the source of the original publication.

You are permitted to download and use the publication for personal purposes. All rights remain with the author(s) and / or copyright owner(s) of this work. Any use of the publication or parts of it other than authorised under article $25 \mathrm{fa}$ of the Dutch Copyright act is prohibited. Wageningen University \& Research and the author(s) of this publication shall not be held responsible or liable for any damages resulting from your (re)use of this publication.

For questions regarding the public availability of this publication please contact openscience.library@wur.nl 


\title{
Mucoraceous moulds involved in the commercial fermentation of Sufu Pehtze
}

\author{
Bei-Zhong Han ${ }^{1,4}$, Angelina F.A. Kuijpers ${ }^{2}$, Nguyen V. Thanh ${ }^{3}$ and M.J. Robert Nout ${ }^{4, *}$ \\ ${ }^{1}$ College of Food Science and Nutritional Engineering, Chinese Agricultural University, Beijing 100083, \\ China; ${ }^{2}$ Centraalbureau voor Schimmelcultures, Fungal Biodiversity Centre, Utrecht, The Netherlands; \\ ${ }^{3}$ Biotechnology Research and Development Institute, Can Tho University, Can Tho, Vietnam; ${ }^{4}$ Laboratory of \\ Food Microbiology, Wageningen University, Wageningen, The Netherlands; *Author for correspondence \\ (e-mail: rob.nout@wur.nl)
}

Received 10 July 2003; accepted in revised form 18 September 2003

Key words: Actinomucor, Mucor, Rhizopus, Phylogenetic relation, Starter, Sufu, Soybean fermentation

\begin{abstract}
Sufu is a fermented cheese-like soybean product in China and Vietnam, obtained by fungal solid-state fermentation of soybean curd (tofu), which results in moulded tofu or 'pehtze'. The final product sufu is obtained by maturing pehtze in a brine containing alcohol and salt during a period of several months. The present report deals with the identity and phylogenetic relationships of mould starter cultures used for the preparation of pehtze. Starter cultures used in commercial pehtze fermentation were obtained from factories located in several provinces of China and Vietnam, isolated from their pehtze and some were obtained from culture collections. They were identified as Actinomucor repens, Actinomucor taiwanensis, Mucor circinelloides, Mocur hiemalis, Mocur racemosus, and Rhizopus microsporus var. microsporus. Phylogenetic relations based on sequencing of genomic DNA of these starters and of relevant control strains from collections indicate that the genera Mucor, Actinomucor and Rhizopus form distinct and homogenous clusters, with Mucor and Actinomucor showing a slightly closer relationship with each other than with Rhizopus.
\end{abstract}

\section{Introduction}

Sufu $(f u-r u)$ is a popular fermented soybean food which has a characteristic flavour and which is commonly consumed as a side-dish during breakfast ( $\mathrm{Su}$ 1986). A very similar product is known as 'Chao' in Vietnam. The preparation of sufu and chao takes place in stages: initially, soybeans are soaked, ground and filtered to obtain soymilk. Next, soy protein is coagulated from the milk; the curd is collected, pressed into sheets and cut to dices of 'tofu'. Tofu is inoculated with a mould starter and incubated 2-7 d at $12-30{ }^{\circ} \mathrm{C}$, resulting in mycelium-covered pieces called 'pehtze' (Han et al. 2001). The starter may either be a pure culture applied as a sprayed suspension, or house-flora which is inoculated onto the tofu by direct contact with utensils. The final stage consists of the maturation of pehtze during several months in a dressing mixture or brine containing alcohol (from rice wine), salt, and several product-specific ingredients for colour and flavour.

The pehtze fermentation is aimed at the formation of a white cover of biomass surrounding the piece of tofu; in addition several proteolytic, lipolytic and other enzymes are formed by the moulds and these will act upon the pehtze during the maturation, causing softening and flavour development (Han et al. 2003). The properties of the mould(s) used for the pehtze fermentation are thus of importance for the quality of the final product. Descriptions of sufu (Han et al. 2001; Su 1986) mention the use of Actinomucor elegans, Actinomucor taiwanensis, Mucor and Rhizo- 
pus spp. as starter cultures, but little recent information is available about starters that are presently applied in commercial practice. The aim of our investigation was to obtain starter cultures used for commercial pehtze preparation, determine or confirm their identity, and study their phylogenetic relations in comparison with relevant strains from culture collections.

\section{Materials and methods}

Strains

Strains collected from commercial pehtze manufacturers included: Actinomucor elegans LU 2025 / AS 3.27 / CBS 111556 from Beijing (LU - Wageningen University; AS - Academia Sinica; CBS - Centraalbureau voor Schimmelcultures), Mucor hiemalis LU 2026 / AS 3.2222 / CBS 111555 from Fujian, Mucor wutungkiao LU 2028 / AS 3.25 / CBS 111557 from Sichuan, Mucor sufu LU 2027 / AS 3.2233 / CBS 111228 from Jiangsu, and Mucor rouxianus LU 2029 / AS 3.2545 / CBS 111229 from Guangdong, all in China. Unidentified strains isolated from commercial pehtze included: LU 2035 / CTT3 / CBS 111562 from An Giang province, LU 2036 / CKP2 / CBS 111563 from Soc Trang province, LU 2033 / CVH1 / CBS 111560 from Dong Thap province, and LU 2034 / CTH4 / CBS 111561 from Dong Thap province all in the Mekong Delta area of Vietnam. Pehtze making strains obtained from mycological collection centers included: Actinomucor taiwanensis CCRC 31159 (maintained by us as LU 2031 and CBS 111558) and Actinomucor elegans CCRC 31342 (maintained by us as LU 2032 and CBS 111559) both purchased from the Food Industry Research and Development Institute, P.O.Box 246, Hsin Chu, Taiwan 30099, China. These strains were deposited with CBS (code numbers given above). Control strains (with CBS and GenBank Accession numbers - GB- in brackets) for parsimony analysis included: Actinomucor elegans (GB AJ278368), Basidiobolus ranarum (GB AY211271), Mortierella alpina (GB AJ271630), Mucor circinelloides (GB AF412287), M. circinelloides f. circinelloides (CBS 478.70 - GB AY243942), $M$. circinelloides f. circinelloides (CBS 195.68 - GB AY243943), M. hiemalis f. corticolus (CBS 106.09GB AY243950), M. hiemalis f. hiemalis (CBS 242.35 - GB AY243949), M. hiemalis f. luteus (CBS 243.35 - GB AY243951), M. hiemalis f. silvaticus (CBS
249.35 - GB AY243948), M. racemosus (GB AJ271061), Rhizopus microsporus v. chinensis (CBS 537.80 - GB AY243957), Rhizopus microsporus v. chinensis (CBS 394.34 - GB AY243961), Rhizopus microsporus v. chinensis (GB AF115732), R. microsporus var. microsporus (CBS 308.87 - GB AY243960), R. microsporus var. oligosporus (CBS 339.62 - GB AY243956), $R$. microsporus var. rhizopodiformis (CBS 343.29 - GB AY243958), and R. oryzae (GB AY211273).

\section{Isolation and maintenance}

All strains were isolated and/or grown on malt extract agar (Oxoid CM59) at 25 and/or $30{ }^{\circ} \mathrm{C}$. They were maintained refrigerated $\left(4^{\circ} \mathrm{C}\right)$ or stored at $-80{ }^{\circ} \mathrm{C}$ in a mixture of equal volumes of malt extract broth (Oxoid CM57) and glycerol, for longer periods. The cultures used for the molecular study were grown on Malt Peptone (MP) broth using 10\% (v/v) of Malt Extract (Brix 10) and 0.1\% (w/v) Bacto Peptone (Difco) in $2 \mathrm{ml}$ of medium in $15 \mathrm{ml}$ tubes. The cultures were incubated at $20^{\circ} \mathrm{C}$ for $5 \mathrm{~d}$ in darkness.

\section{Identification}

Identification was carried out in accordance with Benjamin and Hesseltine (1957), Hesseltine and Ellis (1973), Jong and Yuan (1985) and Scholer et al. (1983) based on macroscopic and microscopic morphology as well as relevant physiological distinctive features.

\section{DNA Extraction, sequencing and analysis}

The total fungal genomic DNA was isolated using FastDNA $^{\circledR}$ Kit (Bio 101, Carlsbad, USA) according to the manufacturer's instructions. Amplification of the two internal transcribed spacers (ITS 1 and ITS 2) including the $5.8 \mathrm{~S} \mathrm{rDNA}$ was performed using the primers LS266 (Masclaux et al.1995) and V9G as proposed by de Hoog et al. (1998). PCR was performed in a $50 \mu \mathrm{l}$ reaction mixture containing 2 $\mu \mathrm{l}$ of genomic DNA $(10-20 \mathrm{ng} / \mu \mathrm{l}), 5 \mu \mathrm{l}$ of PCR buffer, $30 \mu \mathrm{l}$ of ultra pure sterile water, $10 \mu \mathrm{dNTP}$ $(1 \mathrm{mM}), 1 \mu \mathrm{l}$ of each primer $(50 \mathrm{pmol} / \mu \mathrm{l})$ and $1 \mu \mathrm{l}$ Taq polymerase $(2.5 \mathrm{U} / \mu \mathrm{l}$ DNA) (SpaeroQ, Leiden, The Netherlands). Amplification was performed in a GeneAmp PCR system 9700 (AB Applied Biosystems, Nieuwerkerk a/d Yssel, The Netherlands); programmed for 35 cycles of $30 \mathrm{~s}$ denaturation at $94{ }^{\circ} \mathrm{C}$ 


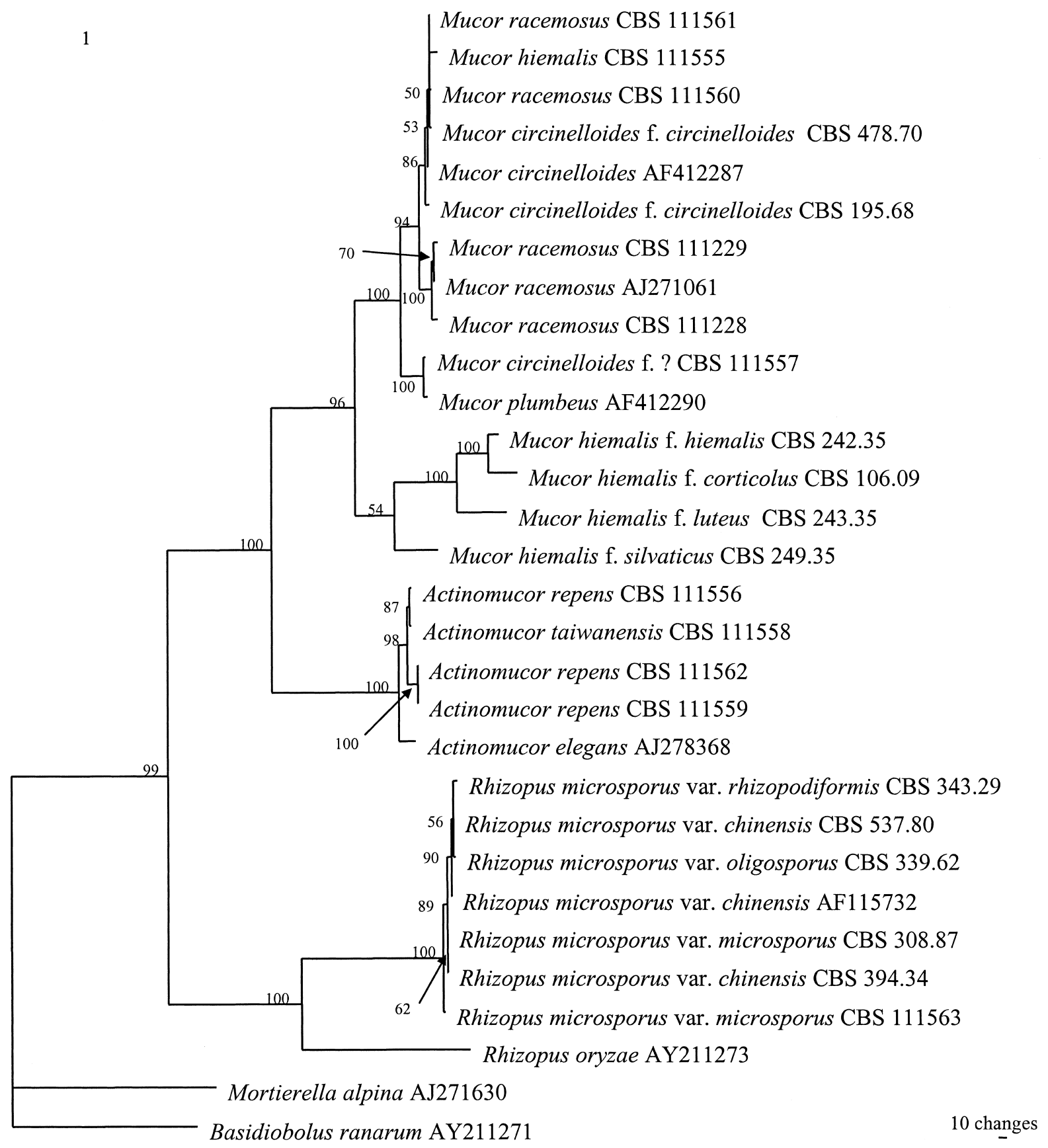

Figure 1. Parsimonious tree obtained from ITS sequences data showing relationships of Mucoraceous moulds involved in sufu pehtze fermentation, compared with relevant collection strains or ITS sequences.

followed by primer annealing $1 \mathrm{~min}$. at $55^{\circ} \mathrm{C}$ and primer extension $1 \mathrm{~min}$. at $72^{\circ} \mathrm{C}$ and a final $4 \mathrm{~min}$. elongation step at $72{ }^{\circ} \mathrm{C}$. After amplification of the ITS 1-5.8S-ITS 2 region, excess primers and dNTP's were removed from the reaction mixture using a commercial GFX column, PCR DNA Purification kit
(Amersham Bioscience, Roosendaal, The Netherlands). The purified PCR fragments were resuspended in $50 \mu l$ of TE buffer. The PCR fragments were directly sequenced in both directions with the primers ITS 1 and ITS 4 (White et. al 1990) using a DYEnamic ET Terminator Cycle Sequencing Kit 
Table 1. Identities of moulds used for commercial sufu pehtze preparation

\begin{tabular}{|c|c|c|c|c|}
\hline Genus & Species & Accession no. & GenBank no. & Origin \\
\hline Actinomucor & repens (elegans) ${ }^{1}$ & CBS $111556^{2}$ & AY243952 & Beijing \\
\hline Actinomucor & repens (elegans) & CBS 111559 & AY243955 & Taiwan \\
\hline Actinomucor & repens (elegans) & CBS 111562 & AY243954 & An Giang \\
\hline Actinomucor & taiwanensis & CBS 111558 & AY243953 & Taiwan \\
\hline Mucor & circinelloides (wutungkiao) & CBS 111557 & AY243947 & Sichuan \\
\hline Mucor & hiemalis & CBS 111555 & AY243944 & Fujian \\
\hline Mucor & racemosus (sufu) & CBS 111228 & AY243945 & Jiangsu \\
\hline Mucor & racemosus (rouxianus) & CBS 111229 & AY243946 & Guangdong \\
\hline Mucor & racemosus & CBS 111560 & AY243941 & Dong Thap \\
\hline Mucor & racemosus & CBS 111561 & AY243940 & Dong Thap \\
\hline Rhizopus & microsporus var. microsporus & CBS 111563 & AY243959 & Soc Trang \\
\hline
\end{tabular}

${ }^{1}$ Alternative species names given in brackets; ${ }^{2} \mathrm{CBS}$ : Centraalbureau voor Schimmelcultures.

(Amersham Bioscience, Roosendaal, The Netherlands). The sequence PCR reaction mixture, total reaction mix is $10 \mu \mathrm{l}$, contained $2 \mu \mathrm{l}$ of template DNA (15-45 ng/ $\mu \mathrm{l}), 4 \mu \mathrm{l}$ Dye terminator RR mix, $3 \mu \mathrm{l}$ ultra pure sterile water and $1 \mu$ primer ITS 1 or ITS 4 ( $4 \mathrm{pmol} / \mu \mathrm{l})$. The reaction was performed in a GeneAmp PCR system 9700 run in 9600 mode (AB Applied Biosystems, Nieuwerkerk a/d Yssel, The Netherlands); programmed for 25 cycles of $10 \mathrm{~s}$ denaturation at $96{ }^{\circ} \mathrm{C}$ followed by primer annealing 5 $\mathrm{s}$ at $50{ }^{\circ} \mathrm{C}$ and primer extension $4 \mathrm{~min}$. at $60{ }^{\circ} \mathrm{C}$. Sequencing products were purified according to the manufacturer's recommendations with Sephadex G-50 superfine column (Amersham Bioscience, Roosendaal, The Netherlands) in a multiscreen HV plate (Millipore, Amsterdam, The Netherlands) and with MicroAmp Optical 96-well reaction plate (AB Applied Biosystems, Nieuwerkerk a/d Yssel, The Netherlands). The samples were analyzed on an ABI Prism 3700 Genetic Analyzer (AB Applied Biosystems, Nieuwerkerk a/d Yssel, The Netherlands). A concensus was computed from the forward and reverse sequences with software package Seqman and Editseq from the lasergene package (DNAStar Inc., Madison, WI). The alignments of the ITS 1-5.8S-ITS 4 sequence data were performed using the software package BioNumerics from Applied Maths and manual adjustments for improvement were made by eye where necessary. The phylogenetic analyses of sequence data were done using PAUP (Phylogenetic Analysis Using Parsimony) version 4.0b10 (Swofford 2000). Alignment gaps were treated as fifth character state, missing data were identified by '?' and all characters were unordered and equal weight. Maximum parsimony analysis was performed for all data sets using the heuristic search option. The robustness of the most parsimonious trees was evaluated by 1000 bootstrap replications (Hillis and Bull 1993). Other measures including tree length, consistency index, retention index and rescaled consistency index (CI, RI and RC) were also calculated. Sequences were deposited at GenBank. Sequences not generated in this study were retrieved from Genbank http:// www.ncbi.nlm.nih.gov and those sequences are mentioned in the Figure with their accession numbers.

\section{Results and discussion}

The identities of the collected strains are listed in Table 1. For some of the taxa, the names as presently listed in the CBS catalogue were used, with the original names in brackets. The majority of sufu pehtze fermentation starters represented species of Mucor and Actinomucor. In addition, one species of Rhizopus was encountered. Considering the effect of climate conditions (temperature, relative humidity) on the distribution, growth and metabolic activity of fungi (Chou et al. 1988; Han et al. 2003) it was hypothesized that species of Mucor and Actinomucor would be abundant in the North, and species of Rhizopus in the South. To the contrary, however, the majority of isolates from the hot and humid Mekong Delta of Vietnam were Mucor and Actinomucor species and only one Rhizopus starter was encountered. Whereas phylogenetic relations for clinically important Mucorales were reported by Voigt et al. (1999), the genus Actinomucor was not included in that study. Because of the importance of Actinomucor as a Sufu Pehtze fermentation inoculum, we investigated its 
phylogenetic relations with the genera Mucor and Rhizopus. Maximum parsimony analysis of the sequence data resulted in 6 equally most parsimonious trees $(\mathrm{TL}=1811$ steps, $\mathrm{CI}=0.730, \mathrm{RI}=0.889$, $\mathrm{RC}=0.649$ ), one of which is shown in Figure 1. The tree was rooted to Mortierella alpina AJ271630 and Basidiobolus ranarum AY211271. Bootstrap support from 1000 replicates are shown at the nodes. Among the cultures tested, distinct and homogenous groups of Mucor, Actinomucor and Rhizopus were observed in the tree (Figure 1). Within the genus Actinomucor, A. taiwanensis is not easily separated from A. repens. In Mucor, M. hiemalis is quite well separated whereas $M$. racemosus and $M$. circinelloides are somewhat mixed. Of the genus Rhizopus, $R$. oryzae AY211273 and $R$. microsporus were included and are separated. $R$. microsporus shows as a homogeneous group; however, the varieties chinensis, microsporus, oligosporus and rhizoides are not easily separated. Earlier, Schostakowitsch [quoted by Benjamin and Hesseltine (1957)] observed - based on conventional morphological criteria - that Actinomисоr is closely related to Mucor but distinct from Rhizopus. However, our DNA-based data would indicate only a slightly closer relation between Mucor and Actinomucor, than with Rhizopus.

\section{Acknowledgements}

The authors thank Roul Emmens, Ewald Groenewald and Robert Samson of the Centraalbureau voor Schimmelcultures, Utrecht, and Birgit Hasenack of Wageningen University, Wageningen, for their valuable contribution.

\section{References}

Benjamin C.R., Hesseltine C.W. 1957. The genus Actinomucor. Mycologia 49: 240-249.

Chou C.C., Ho F.M. and Tsai C.S. 1988. Effects of temperature and relative humidity on the growth of and enzyme production by
Actinomucor taiwanensis during sufu pehtze preparation. Appl. Environ. Microbiol. 54: 688-692.

Han B.Z., Ma Y., Rombouts F.M. and Nout M.J.R. 2003. Effects of temperature and relative humidity on growth and enzyme production by Actinomucor elegans and Rhizopus oligosporus during sufu pehtze preparation. Food Chem. 81: 27-34.

Han B.Z., Rombouts F.M. and Nout M.J.R. 2001. A Chinese fermented soybean food. Int. J. Food Microbiol. 65: 1-10.

Hesseltine C.W., Ellis J.J. 1973. Mucorales. In: The Fungi, Vol IVb, Chapter 11 (pp. 187-217). Academic Press, Inc, New York, New York, USA.

Hillis D.M. and Bull J.J. 1993. An empirical test of bootstrapping as a method for assessing confidence in phylogenetic analysis. Systematic Biology 42: 182-192.

Hoog G.S. de, Gerrits van den Ende A.H.G. 1998. Molecular diagnostics of clinical strains of filamentous basidiomycetes. Mycoses. 41: 183-189.

Jong S.C., Yuan G.F. 1985. Actinomucor taiwanensis sp. nov., for manufacture of fermented soybean food. Mycotaxon. 23: 261264.

Masclaux F., Guého E., Hoog G.S. de, Christen R. 1995. Phylogenetic relationships of humanpathogenic Cladosporium (Xylohypha) species inferred from partial LS rRNA sequences. J. Med. Vet. Mycol. 33: 327-338.

Scholer H.J., Müller E. and Schipper M.A.A. 1983. Mucorales. In: Howard D.H. (ed.), Fungi pathogenic for humans and animals (in 3 parts). Part A: Biology, Chapter 2 (pp. 9-60), Mycology Series Vol 3. Marcel Dekker, New York, USA.

Su Y.C. 1986. Sufu. In: Reddy N.R., Pierson M.D. and Salunkhe D.K. (eds), Legume-based fermented foods (pp. 69-83). C.R.C. Press, Boca Raton., Florida, USA.

Swofford D.L. 2000. PAUP* 4.0: phylogenetic analysis using parsimony. Sinauer Associates, Sunderland, Massachusetts, USA.

Voigt K., Cigelnik E. and O’Donnell K. 1999. Phylogeny and PCR identification of clinically important Zygomycetes based on nuclear ribosomal-DNA sequence data. J. Clinical Microbiol. 37: 3957-3964.

White T.J., Bruns T., Lee S., and Taylor J. 1990. Amplification and direct sequencing of fungal ribosomal RNA genes for phylogenetics. In: Innis M.S. and Gelfand D.H. (eds), PCR protocols: a guide to methods and applications. (pp. 315-322). Academic Press, New York, New York, USA. 